\title{
DIFFICULT AIRWAY MANAGEMENT IN EMERGENCY SURGERY: INTUBATION THROUGH LARYNGEAL MASK
}

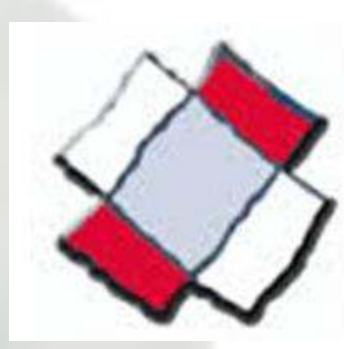

Complejo Asistencial de Zamora

Sanchis Dux, R. (1); Fuentetaja Sanz, Fernando(1); Ruíz Simón, FA(1); Molero Diez, YB. (1); Sánchez Hernando, V. (2); Sánchez Tabernero, $A^{(2)}$.

1) Resident of Anesthesiology and Reanimation, Hospital Virgen de la Concha, Zamora (Spain)

\section{Euroanaesthesia}

COPENHAGEN 02-04 JUNE

2) Associate Doctor of Anesthesiology and Reanimation, Hospital Virgen de la Concha, Zamora (Spain)

\section{BACKGROUND}

Prediction of difficult intubation and ventilation is essential and challenging. Airway devices have been favorable for managing these situations but, sometimes, a secure airway is not possible. Endotracheal intubation through laryngeal mask with fibrobronchoscope is an effective and secure way to ensure airway permeability and ventilation.

\section{CASE REPORT}

51-year-old woman was required emergency laparoscopic cholecystectomy. Past medical history: bipolar syndrome, fibromyalgia and necrosis of temporomandibular joint which required surgery in 2014, with prosthesis implantation. Airway examination: regular neck length with excellent cervical extension, thyromental distance higher than $6 \mathrm{~cm}$, mouth opening of less than 4 $\mathrm{cm}$, Mallampati III.

We used rapid sequence intubation with fentanyl, Propofol and rocuronium and first attempt was done with laryngoscope, and no structures couldn't be visualized. We chose Airtrag number 3 with endotracheal tube 7 for second attempt and, due to limited mouth opening, manipulation of airtraq wasn't possible and intubation was unsuccessful. We performed manual ventilation and we decided to place a laryngeal mask Ambu Aungain \#3.

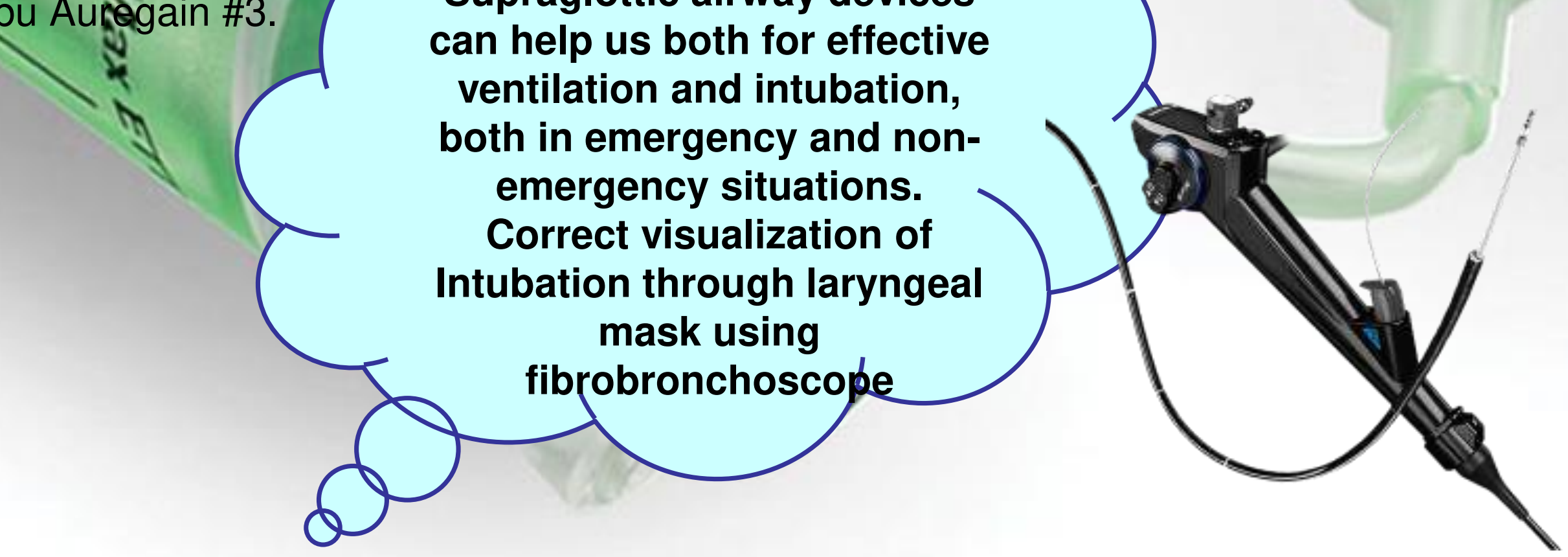

After starting mechanical ventilation, we tried to introduce a stomach tube through laryngeal mask gastric channel, being this attempt unsuccessful and gastric content with air couldn't be aspirated. Due to this finding, possible misplacement of supraglottic device was considered and we decided to perform fibrobronchoscope intubation through laryngeal mask. Intubation with ET was successful, and aspiration was performed. No other incidences were found during extubation. We explained the situation to our patient and we wrote an alert of difficult airway management for future intubations.

\section{DISCUSSION}

Features for difficult airway intubation were found in this patient. Using supraglottic devices and others are essential in our daily practice for these cases, but sometimes, a total correct placement is not possible. Endotracheal intubation with fibrobronchoscope through laryngeal mask is a safe and effective option for intubation and ensuring airway permeability when objective findings about misplacement are seen during

ventilation.

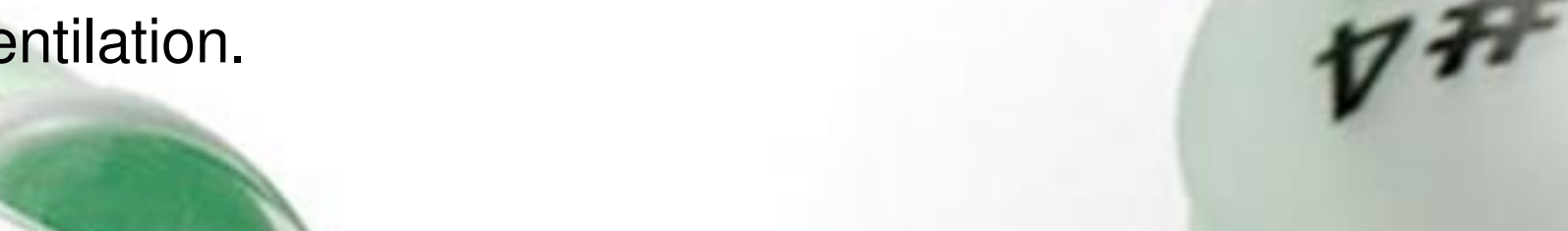

Panel Michalek, Philip Hodgkinson, William Donaldson. Fiberoptic intubation through an I-Gel supraglottic airway in two patients with predicted difficult and intellectual disability. Anesth Analg 2008; 106(5): 1501-4.

Donald M. Miller. A proposed classification and scoring system for supraglottic Sealing Airways: A brief review. Anest Analg 2004; 99: 1553-9 